\title{
AN OVERVIEW OF THE URBAN BOUNDARY LAYER ATMOSPHERE NETWORK IN HELSINKI
}

\author{
By C. R. WOOd, L. JärVI, R. D. Kouznetsov, A. Nordbo, S. Joffre, A. Drebs, T. Vihma,
} A. HiRsikKo, I. SUOMI, C. Fortelius, E. O’Connor, D. Moiseev, S. HaApanala, J. Mollanen, M. Kangas, A. Karppinen, T. Vesala, AND J. KuKKonen

A dedicated intensive research-grade observational network in Helsinki enables studies of the physical processes in the urban atmosphere at high latitude.

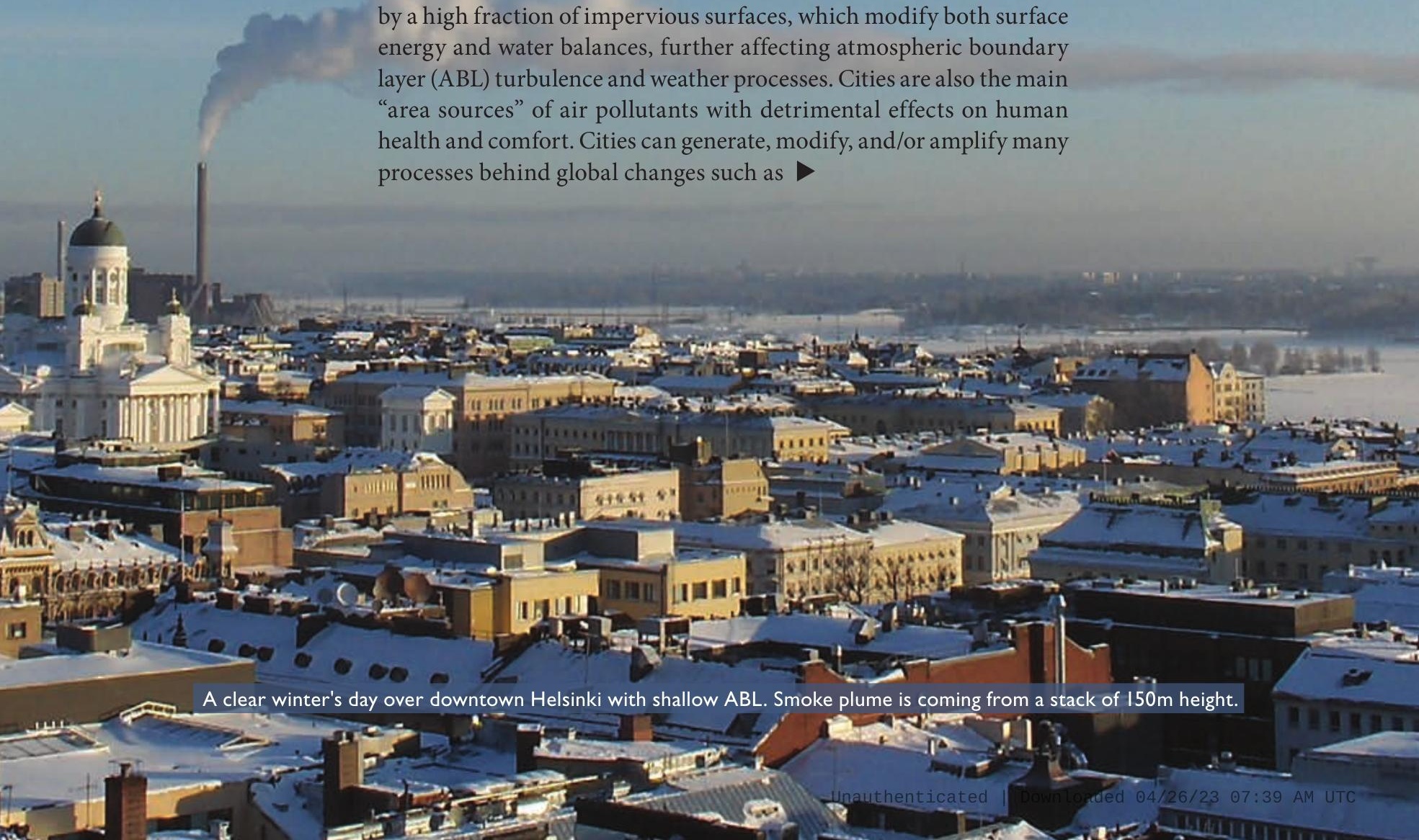

A lthough urban areas comprise a very small fraction of Earth's land cover (Schneider et al. 2009), over half of global population live in urban agglomerations. Therefore, it is important to monitor, understand, and predict the modifications occurring in local weather and climate due to urbanization, particularly for the perspective of accurate high-resolution weather and air-quality forecasting and climate-sensitive urban design and planning. Cities are characterized by a high fraction of impervious surfaces, which modify both surface energy and water balances, further affecting atmospheric boundary layer $(\mathrm{ABL})$ turbulence and weather processes. Cities are also the main "area sources" of air pollutants with detrimental effects on human health and comfort. Cities can generate, modify, and/or amplify many processes behind global changes such as 
increases in greenhouse gas concentrations, increased water and energy demand, environmental pollution, or change of biodiversity. Moreover, the recent increase of spatial resolution in numerical weather prediction (NWP) models and the improved treatments of model physics and chemistry in NWP and chemical-transport models demand a more realistic representation of urban features, processes, and feedbacks in these models (Kukkonen et al. 2012). Therefore, we need dedicated and long-term monitoring of urban meteorological processes.

Long-term urban ABL observations at different spatial and temporal scales using various instruments have been made in few cities (Rotach et al. 2002; Grimmond 2006), and most studies have not used state-of-theart equipment for long periods. Since the pioneering Metropolitan Meteorological Experiment (METROMEX) urban study in St. Louis (Changnon et al. 1971), the more recent comprehensive studies include the cities of Basel, Switzerland (Rotach et al. 2005); Marseille, France (Cros et al. 2004); Oklahoma City, United States (Allwine and Flaherty 2006); New York, United States (Hanna et al. 2006); Toulouse, France (Masson et al. 2008); Montreal and Vancouver, Canada (www.epicc .ca); and London, United Kingdom (Wood et al. 2009; Harrison et al. 2012). Most studies have focused on specific campaigns, often with less than one year of measurements and have concentrated on midlatitude cities. To date, most high-latitude urban ABL research

AfFiliations: WoOd, JofFre, Drebs, ViHMA, HiRsiKKo,* SUOMI, Fortelius, Kangas, Karppinen, and KuKKonen-Finnish Meteorological Institute, Helsinki, Finland; JärVI, Nordbo, HaApanala, MoILANen, AND Vesala_Department of Physics, University of Helsinki, Helsinki, Finland; Kouznetsov—Finnish Meteorological Institute, Helsinki, Finland, and Obukhov Institute of Atmospheric Physics, Moscow, Russia; O'ConNoR-Finnish Meteorological Institute, Helsinki, Finland, and Department of Meteorology, University of Reading, Reading, United Kingdom; MoIseev-Finnish Meteorological Institute, Helsinki, Finland, and Department of Physics, University of Helsinki, Helsinki, Finland

*CURRENT AFFILIATION: Forschungszentrum Jülich $\mathrm{GmbH}$, Institut für Energie-und Klimaforschung: Troposphäre (IEK-8), Jülich, Germany

CORRESPONDING AUTHOR: C. R. Wood, Finnish Meteorological Institute, Erik Palménin aukio I, Fl-00I0I, Helsinki, Finland

E-mail: curtis.wood@fmi.fi

The abstract for this article can be found in this issue, following the table of contents.

DOI: 10.1175/BAMS-D-12-00146.I

A supplement to this article is available online (10.II75/BAMS-D-12-00146.2)

In final form 12 March 2013

(C)2013 American Meteorological Society has used solitary or few point measurements (Eresmaa et al. 2006; Mårtensson et al. 2006; Lemonsu et al. 2008; Vesala et al. 2008; Järvi et al. 2009a; Bergeron and Strachan 2012; Nordbo et al. 2012a). Thus, there is a clear lack of intensive research-grade long-term ABL observations, especially from high-latitude cities, with their associated pronounced annual variations in meteorological conditions and continuous snow cover that can last several months (Lemonsu et al. 2010). These conditions might create extreme meteorological conditions, such as strong ground-based or elevated inversions (Kukkonen et al. 2005) with detrimental air-quality implications.

An extensive mesoscale effort (Helsinki Testbed) centered around the Helsinki metropolitan area has been running several years (core data years 2005-09) covering a $150 \times 150 \mathrm{~km}^{2}$ area of southern Finland and northern Estonia (Koskinen et al. 2011). In addition to this mesoscale observational network, the Station for Measuring Ecosystem-Atmosphere Relations III (SMEAR-III) urban measurement station has been running in Helsinki since 2004 (Järvi et al. 2009b). The station concentrates on observing surface-atmosphere exchange processes at a micrometeorological scale, in particular using the eddy-covariance (EC) method to directly measure vertical turbulent fluxes of momentum, sensible and latent heat, and carbon dioxide (Vesala et al. 2008; Järvi et al. 2012; Nordbo et al. 2012a,b).

Combining those observations with additional state-of-the-art observations has enabled a new observational research-intensive network, the Helsinki Urban Boundary-Layer Atmosphere Network (UrBAN; http://urban.fmi.fi). Our aim is that the network will improve our understanding of urban ABLs by including measurements of a wide variety of processes at a range of scales. The observations in the network are complemented with model developments, such as NWP and meteorological preprocessing of air-quality (see online supplemental material).

The long-term purposes of Helsinki UrBAN are to

1) understand the processes in Helsinki's ABL, as affected by a range of surfaces within a few kilometers (urban, suburban, and sea) and the strong climatic seasonality;

2) provide better experimental data for developing and evaluating numerical models such as NWP, meteorological preprocessing, and air-quality models (see online supplemental material); and

3) provide results that will support improvements in relevant applications such as city planning, building design, and energy use. 
The aim of this article is to describe the network, show selected results, and remark on potential future use of the results of the network.

THE NETWORK. An overview of observing site locations and instrumentation for studying Helsinki's ABL is displayed in Fig. 1 and Table 1. We define downtown Helsinki as the central area of buildings that are densely packed with a regular layout (Nordbo et al. 2012a): that is, approximately the land area south of $60.18^{\circ} \mathrm{N}$ (encompassing the observation sites of Torni, Fire Station, Sitra, and Kaisaniemi) (see sidebar on the climate and topography of Helsinki).

In situ equipment and main sites. The EC measurements of turbulent fluxes are made at three sites in Helsinki: Kumpula, Fire Station, and Torni.

On the Kumpula campus, next to the Finnish Meteorological Institute (FMI) and University of Helsinki buildings, is the SMEAR-III mast (Järvi et al. 2009b). This semi-urban site, located around $4 \mathrm{~km}$ northeast from downtown Helsinki, has developed as a core site of focused activity for intercomparison of instruments and a deeper understanding of processes at one site. EC measurements at Kumpula have been ongoing since 1 December 2005 (Vesala et al. 2008; Järvi et al. 2009b,c). The flux measurements are carried out atop a 31-m-high lattice mast (the base being $26 \mathrm{~m} \mathrm{MSL}$ ), with possible mast flow distortion from $0^{\circ}$ to $50^{\circ}$. It is characterized as a semi-urban
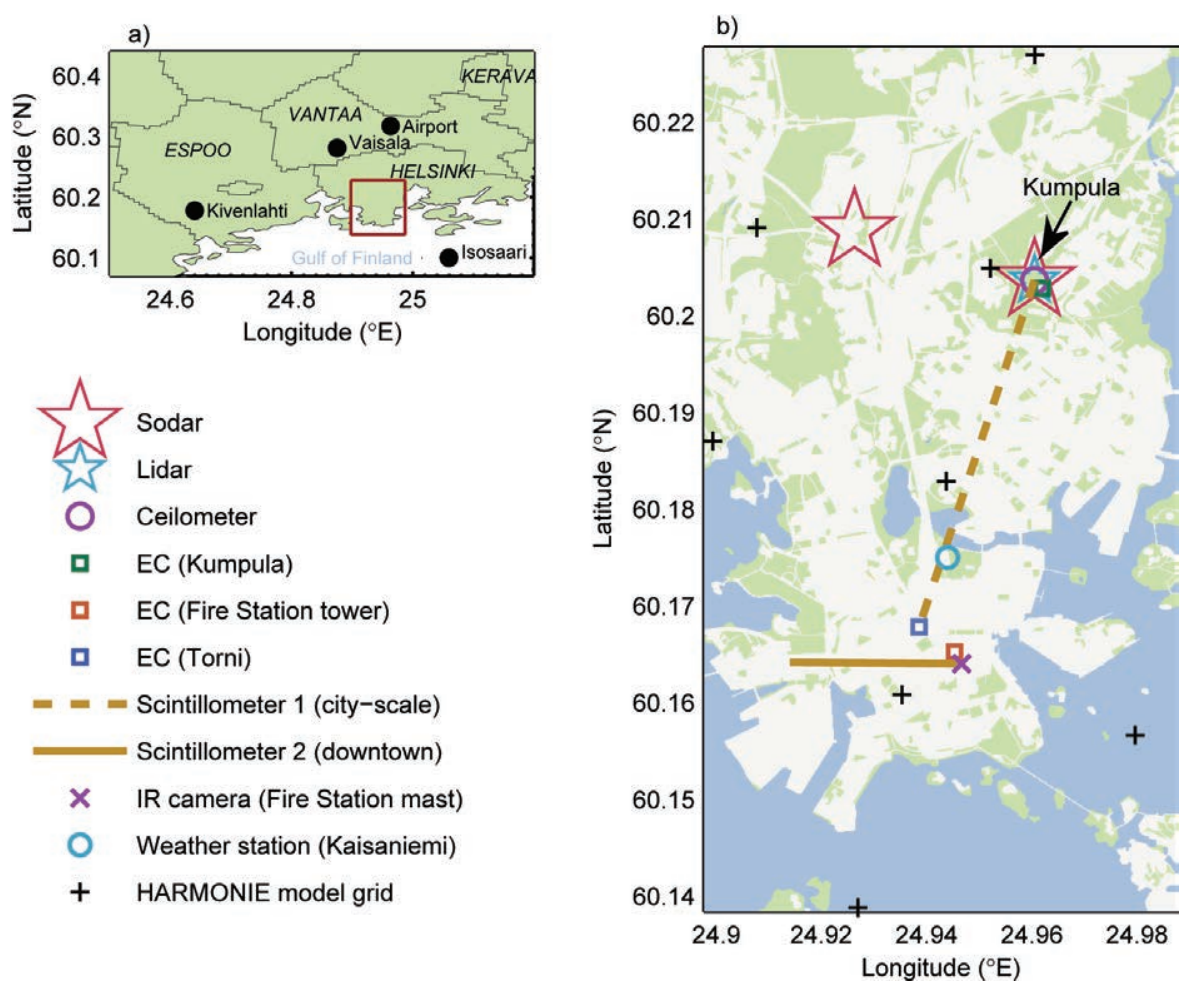

measurement site, given that three different surface cover areas (road, vegetation, built) can be distinguished within about a kilometer around the mast, allowing separate analysis of fluxes for those upwind surfaces. The mean height of the nearby buildings $\left(z_{\mathrm{H}}\right)$ in the built sector is $20 \mathrm{~m}$ (and only $8.4 \mathrm{~m}$ averaged for the whole sector within a 1-km radius), so the flux measurements are carried out at $1.6 z_{\mathrm{H}}$ with respect to the nearby buildings. Detailed description of the site and measurements can be found elsewhere (Vesala et al. 2008; Järvi et al. 2009c; Nordbo et al. 2012a).

The other two EC sites, Fire Station and Torni, are located downtown within a distance of only $500 \mathrm{~m}$ from each other (Nordbo et al. 2012a). Those locations are among the highest possible locations in downtown Helsinki, and their source areas can be estimated at about a kilometer radius depending on atmospheric stability and wind direction (Nordbo et al. 2012a). At the Fire Station, flux measurements began on 28 June 2010 (the measurements had to stop on 27 January 2011 because of building refurbishments and to date have not resumed yet). Measurements were made on top of the 38 -m-high tower (the base is $23 \mathrm{~m} \mathrm{MSL}$ ) with mast flow distortion from $90^{\circ}$ to $180^{\circ}$. The tower itself is $8.8 \mathrm{~m} \times 8.8 \mathrm{~m}$, and a pole was installed on top of it in northwest corner so that the measurements were carried out $42 \mathrm{~m}$ AGL (above ground level). At Torni, the measurements have been ongoing since 28 September 2010. The measurements are made $60 \mathrm{~m}$ AGL (ground at $15 \mathrm{~m} \mathrm{MSL}$ ) with mast flow distortion from $50^{\circ}$ to $185^{\circ}$, where a 2.3-m-high pole

Fig. I. Maps of Helsinki with equipment locations marked. (a) Shown are profile masts at Kivenlahti and Isosaari island, Vaisala site, and airport. The extent of the area shown in (a) is approximately $38 \mathrm{~km}$ latitude by 38 km longitude. (b) Land-use map: urban/paved (white), vegetative (green), and water (blue) (HSY 2008). The red box in (a) shows the area in (b). The sodar moved from Kumpula westward to Pasila. The grid points of the HARMONIE model are $2.5 \mathrm{~km}$ spacing on Lambert conformal plane (see online supplemental materials). 


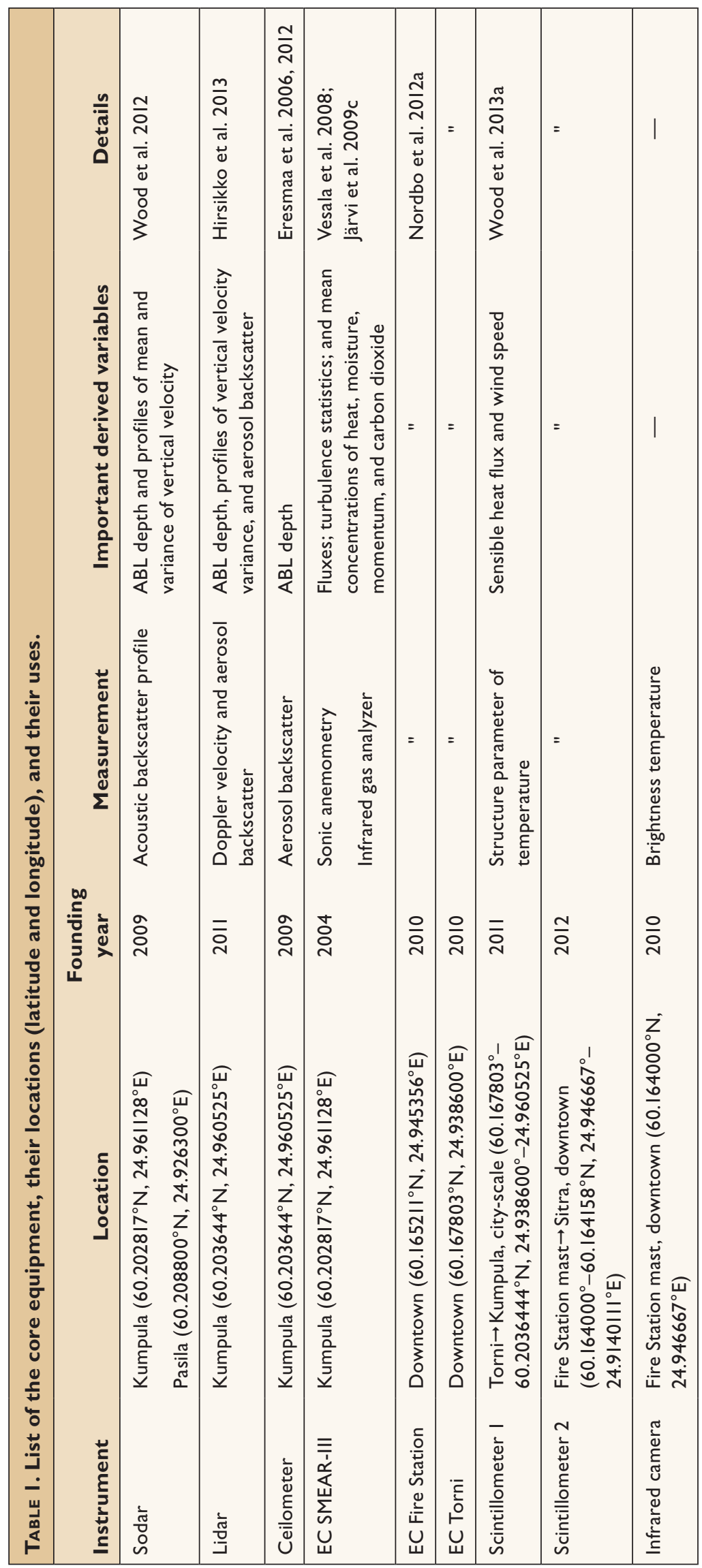

is installed. The details of these measurements-including building configuration, instrumental layout, and footprint analysis-can be found in Nordbo et al. (2012a). The surrounding area of both sites is highly built up with the fraction of impervious surfaces, including buildings and paved surfaces, being above $80 \%$ inside a $1-\mathrm{km}$-radius circle. In downtown Helsinki, buildings are reasonably well packed and uniform and variation as a function of wind direction within the footprint of Torni EC site are as follows: mean building heights $z_{\mathrm{H}}=19-29 \mathrm{~m}$, aerodynamic roughness length $z_{0}=0.9-1.9 \mathrm{~m}$, and zero-plane displacement height $z_{\mathrm{d}}=$ 12-18 m (following morphological methods from building databases; Nordbo et al. 2012a). The building height and roughness length do not vary much with distance from the tower (thus reducing uncertainty in source-area estimates), although they vary slightly as a function of wind direction. Both downtown EC stations are at about 2-3 times the mean building height and 9-50 $\left(z-z_{\mathrm{d}}\right) / z_{0}$ (Nordbo et al. 2012a). For comparison, although there are EC measurements at a range of heights within and above the urban canopy across the globe, most urban EC sites range between 0.4 and 500 $\left(z-z_{\mathrm{d}}\right) / z_{0}$ and up to $22 z_{\mathrm{H}}$ (Roth 2000; Nordbo et al. 2012a).

At all three EC sites, the fluxes (of momentum, sensible heat, latent heat, $\mathrm{CO}_{2}$, and aerosol particle number) are measured with the well-established EC method (Aubinet et al. 2012). The configurations comprise a three-dimensional sonic anemometer, infrared gas analyzers for measuring the $\mathrm{CO}_{2}$ and water-vapor fluctuations, and water condensation particle counters for measuring particle number concentrations. Raw eddycovariance data are logged at $10 \mathrm{~Hz}$ for postprocessing, and fluxes are 
calculated with 30 -min averaging according to standard methods (Nordbo et al. 2012c).

Furthermore, values of the structure parameter of temperature $\left(C_{\mathrm{T}}{ }^{2}\right)$ are estimated from $10-\mathrm{Hz}$ time series of instantaneous sonic temperature measured by the sonic anemometers. Data from sonic anemometers and scintillometers (see below) can thence be readily compared using $C_{\mathrm{T}}^{2}$. The spectrum-modelfitting method (Kouznetsov and Kallistratova 2010; Wood et al. 2013a) is used with 1024-point (10 s) segments over 10 -min intervals. The method uses the Welch periodogram spectra to fit the model spectrum that accounts for the internal noise of measurements and for the Nyquist effect of sampling. The approach implicitly assumes stationarity of the sonic data series.

Comprehensive aerosol particle and gas pollutant measurements are carried out at Kumpula. These include size-resolved aerosol particle number concentration, ozone, nitrogen oxides, carbon monoxide, and sulfur dioxide (Hussein et al. 2008; Järvi et al. 2009b), as well as detailed aerosol chemical composition (Saarnio et al. 2010). Turbulent fluxes of total number concentration are measured at both Kumpula (Järvi et al. 2009d; Ripamonti et al. 2013) and Torni. A summary of the range of air-quality observations across the Helsinki metropolitan area (HSY) can be found elsewhere (www.airquality.fi). Briefly, air quality is monitored at 11 stations (7 permanent and 4 mobile), with live HSY website updates. Typical observations include $\mathrm{PM}_{10}, \mathrm{PM}_{2.5}$, nitrogen dioxide, nitrogen monoxide, ozone, sulfur dioxide, volatile organic compounds, and carbon monoxide.

Additional measurements made at Kumpula include wind and temperature profiles at heights of $4,8,16$, and $32 \mathrm{~m}$. Other measurements include the radiation components and photosynthetically active radiation, at 31-m height.

Downtown, on a lattice mast $90 \mathrm{~m}$ east of the Fire Station tower (Fig. 1), a radiation-balance sensor and two radiation thermometers are mounted at $53 \mathrm{~m}$ AGL and about 30-40 $\mathrm{m}$ above the roof level of the surroundings. The primary purpose of the radiation thermometers is to provide a reference for the thermal camera readings (see below) and to evaluate the effect of spatial inhomogeneity on integral thermal properties of the urban surface. One of the radiation thermometers is looking westward at the camera's field of view and another one is $45^{\circ}$ below the camera-view axis.

In addition, four infrared radiation sensors have been mounted at Torni to measure surface temperatures of four surfaces in different orientations. They are located at 36-38 m AGL. They are measuring a black sheet-metal roof, a concrete floor, and concrete walls.

Finally, FMI has several operational automatic weather stations across Finland that record temperature, humidity, wind speed and gusts, precipitation, cloud coverage, wind direction, atmospheric pressure,

\section{CLIMATE AND TOPOGRAPHY OF HELSINKI}

Helsinki, the capital city of Finland, had approximately 596,000 inhabitants in 2012 (density of $2789 \mathrm{~km}^{-2}$ ), although the H Helsinki metropolitan area (defined as the municipalities of Helsinki, Espoo, Vantaa, and Kauniainen) has about I.I million inhabitants $\left(1377 \mathrm{~km}^{-2}\right)$ (Population Register Center of Finland 2012). Helsinki is located on the north shore of the Gulf of Finland in the Baltic Sea. Because of the influence of the vicinity of the sea, as well as oceanic-scale features such as the North Atlantic Drift, winter temperatures are higher than the far northern location might suggest, resulting in a humid continental climate (Köppen-Geiger climate classification Dfb). The annual mean air temperature is $+5.9^{\circ} \mathrm{C}$ (period 198I-2010), with the lowest monthly average temperature in February of $-4.7^{\circ} \mathrm{C}$ and the highest monthly average temperature in July of $+17.8^{\circ} \mathrm{C}$ (Pirinen et al. 2012). Monthly average sunshine hours vary from $25 \mathrm{~h}$ in December to $280 \mathrm{~h}$ in June. Precipitation amounts are moderate, where the average annual precipitation sum is $655 \mathrm{~mm}$, with the highest monthly average in August $(80 \mathrm{~mm})$ and the lowest in April $(32 \mathrm{~mm})$. The average number of days with precipitation exceeding $1 \mathrm{~mm}$ varies all year round from 7 to 12 days per month. Because of the vicinity of the Gulf of Finland, long spells of dry and hot weather are rare, unless synoptic conditions dictate: for example, a long period of easterly flow occurs in the summer.

In winter, the sea is typically ice covered but can be open or partly open. In winter conditions of an open sea during coldair outbreaks, the sea surface may be $20^{\circ}-30^{\circ} \mathrm{C}$ warmer than the air above it. This may result in turbulent fluxes of sensible and latent heat totaling several hundreds of watts per square meter, resulting in a development of a convective boundary layer (Vihma and Brümmer 2002; Tammelin et al. 2012). In summer, the sea surface temperature may vary in time and space because of upwelling in the sea. During coastal upwelling, the sea surface temperature may rapidly drop by up to $10^{\circ} \mathrm{C}$, causing stabilization of the $A B L$ and fog formation (Suomi 2004).

Topographical changes in Helsinki are very slight and most of the metropolitan area is less than $50 \mathrm{~m}$ above mean sea level (MSL). Helsinki has heterogeneity at the kilometer scale with urban, suburban, forest, grassland, and sea (open or frozen) (Fig. I). Most of the city is low rise, with few buildings above $60 \mathrm{~m}$. 
snow depth, and visibility. Around 10 of these are within the area on Fig. 1a. Two reference sites worthy of mention include Kaisaniemi-where air temperature has been recorded since 1838-and HelsinkiVantaa airport, useful for inland conditions (Fig. 1).

Spatially resolving and spatially averaging equipment. A single-antenna vertical sodar (Kouznetsov 2007, 2009) was located at Kumpula (on the FMI roof) from 14 August 2009 to 5 September 2011 but was moved westward $2.3 \mathrm{~km}$ to another semi-urban site (Pasila) from 29 March 2012 onward. The repetition frequency is $5 \mathrm{~s}$, and the sounding range is $20-400 \mathrm{~m}$ above the antenna, with a vertical resolution of $10 \mathrm{~m}$. The Doppler shift of the echo signal is used to evaluate the vertical-velocity component. During the echosignal processing for each range gate, the scattering intensity and the velocity are evaluated. To distinguish the echo signal from the noise, the noise level is evaluated in adjacent frequency bands. The two key outputs are (i) profiles of vertical-velocity variance and (ii) the diagnosis of ABL depth when it is within the sodar's range using the minimum in backscatter gradient profile (Wood et al. 2012).

A pulsed scanning Doppler lidar (Pearson et al. 2009) has been operating at Kumpula (on FMI roof) since 1 September 2011 operating at $1.5-\mathrm{mm}$ wavelength and equipped with a depolarization channel receiving backscattering signal from aerosol particles and hydrometeors (i.e., cloud/fog droplets and ice crystals). Primary data processing includes noise removal from clear-sky data based on signalto-noise ratio and a standard self-calibration procedure (O'Connor et al. 2004). The observation range is $90-9600 \mathrm{~m}$, with $30-\mathrm{m}$ resolution. Low aerosol concentration-typical for poleward sites-affects lidar data quality, which requires careful optimization of integration time and beam focus. Data availability is variable but, since typically a 5-s interval or longer time is needed to improve the signal-to-noise ratio, the current integration time is $20 \mathrm{~s}$. In addition to vertical profiles of aerosol and vertical velocity, Doppler scanning (beam swinging) techniques enable the collection of vertical profiles of horizontal wind speed vectors. Novel scanning strategies may enable the study of estimates of a horizontal transect of horizontal wind vectors (Wood et al. 2013b), turbulent mixing and dynamics of the ABL (Barlow et al. 2011), and sensible heat and momentum flux (Collier et al. 2005). Performance of the lidar was investigated during a 2-week intercomparison campaign in Helsinki (Hirsikko et al. 2013) against FMI's other Doppler lidars showing good agreement for the wind vector profiles. From 2013 onward, these ABL wind and aerosol profiles will be complemented with a radio acoustic sounding system (SODAR-RASS) instrument for temperature and wind profiles.

FMI has five operational ceilometers within $50 \mathrm{~km}$ of central Helsinki-Kumpula, Helsinki-Vantaa airport ( $14 \mathrm{~km}$ north), Isosaari island ( $\sim 8 \mathrm{~km}$ southeast and $\sim 7 \mathrm{~km}$ off the Finnish coast), Nurmijärvi ( $50 \mathrm{~km}$ north of downtown Helsinki), and Porvoo ( $\sim 50 \mathrm{~km}$ east) - but are configured to provide just cloud base. Two ceilometers have continuously logged profile measurements: at Kumpula from 22 June 2009 onward (Vaisala CL31) and at the FMI radiosounding observatory of Jokioinen (about $100 \mathrm{~km}$ northwest of Helsinki; Vaisala CL51). In addition, some investigations have been performed using ceilometer profile data from specific experiments in suburban Helsinki (Vaisala, Vantaa; Fig. 1) to estimate ABL depth (Eresmaa et al. 2006, 2012).

Two boundary layer scintillometers (BLS900) were installed in central Helsinki. A 4.1-km "city scale" path has been operating since 5 July 2011 on a near south-north path from downtown (Torni) to semiurban Kumpula $\left(198^{\circ}\right.$ bearing) and the beam is about 40-60 m AGL ( 10-40 $\mathrm{m}$ above building height). The second downtown BLS was installed on 2 March 2012 in a roughly east-west $1.8-\mathrm{km}$ path across downtown Helsinki at a height of 50-70 m AGL (271 ${ }^{\circ}$ bearing) from the Fire Station mast to the Sitra building. The Sitra building is located on the western edge of the densely packed buildings downtown. The source area of the second scintillometer is downtown and thus qualitatively corresponds to much of the source area of the downtown (Torni) EC measurements, where building heights are 19-29 m. These scintillometers give a spatially integrated value of the refractive-index structure parameter $\left(C_{n}{ }^{2}\right)$ and cross-beam horizontal wind component. The parameter $C_{n}^{2}$ can readily be converted to $C_{\mathrm{T}}^{2}$, but conversion to sensible heat flux requires many assumptions and is most readily applied only during free convection (Zeweldi et al. 2009). The path weighting of the instrument is such that most of the signal comes from the center of the beam (Hill and Ochs 1978; Scintec 2011). The scintillometer measurements require good visibility; thus, no data come during fog or precipitation (Uijlenhoet et al. 2011).

An infrared camera is installed on the Fire Station mast with a westward view across downtown in order to cover a part of the footprint of the Torni EC and the downtown scintillometer measurements. The camera has $48 \times 47$ pixels and $60^{\circ} \times 60^{\circ}$ view area. This results in effective horizontal resolution of about 
$10 \mathrm{~m}$ close to the camera. The images are acquired and stored every $5 \mathrm{~s}$. No corrections are yet applied to the camera data. Despite the absolute thermal accuracy being poor $( \pm 3 \mathrm{~K})$, thermal inhomogeneities within a fraction of a degree can be measured. The camera is affected by the thermal anisotropy of the urban surface and thus should be used with care. Therefore, it is more useful for relative comparison of thermal sources in any investigated direction in order to help for the analyses of scintillometer data or case studies.

These spatially averaging instruments are a key addition to point measurements in order to assess model grid values. Helsinki UrBAN will support FMI's goal of developing within the High-Resolution Limited-Area Model (HIRLAM)-Aire Limitée Adaptation Dynamique Développement International (ALADIN) framework its new operational nonhydrostatic HIRLAM-ALADIN Research on Mesoscale Operational NWP in Euro-Mediterranean Partnership (HARMONIE) limited area model with $2.5-\mathrm{km}$ horizontal resolution that includes the urban Town Energy Balance module (Masson 2000). Supporting information on model developments along with more details on instrument manufacturers and a summary of some auxiliary instruments to Helsinki UrBAN are provided in the online supplemental material.

OBSERVATIONS OF HELSINKI'S ATMOSPHERE. We now present examples as a testimony to the potential of the network.

Seasonality and diurnal cycle. One of the main drivers determining the climate of Helsinki is the strong seasonality of net all-wave radiation $Q^{*}$. A greater daytime $Q^{*}$ is observed downtown than at semiurban Kumpula for most times in the year and day (Fig. 2a). In late winter (January-March), the lower $Q^{*}$ values are mainly caused by the snow cover, which increases the surface albedo and causes a large amount of $K \uparrow$ (Fig. 2b), especially at the semi-urban Kumpula site, whereas less snow is observed downtown. We hypothesize that the large difference is due to (i) the extensive snow clearing from roads, footpaths, and roofs downtown and (ii) energy balance differences such as increased long wave radiation from the vertical snow-free walls, building heat storage, and anthropogenic heat emissions. During snow-free periods (May-October), the surface albedo is slightly higher at Kumpula $(0.13 \pm 0.01)$ compared to downtown ( 0.11 $\pm 0.01)$. This higher albedo can be explained by the higher fraction of vegetation cover in Kumpula as vegetation has typically higher reflectivity than built surfaces (Oke 1987). Interestingly, only slightly higher upward longwave radiation is measured downtown than Kumpula (not shown). Lower $Q^{*}$ in Kumpula could also be explained by atmospheric pollutants or humidity, which might affect the downward radiation components especially in spring when typically intensive resuspension of road gravel takes place (Kupiainen et al. 2011). However, since Helsinki's air pollution is typically relatively low (except in spring; Järvi et al. 2009b), this would require more detailed investigations with respect to, for example, wind direction, thus yielding possible explanations from the prevailing downwind position of Kumpula with regard to downtown during these months and/or from local sources of pollution, moisture, or secondary organic particles (from vegetation). The large wintertime difference in $K \uparrow$ between downtown and Kumpula emphasizes the importance of snow in the radiation balance and further in the energy partitioning and in energy balance models. Previously, this has been only marginally studied (Lemonsu et al. 2008, 2010; Bergeron and Strachan 2012), and thus our network could provide important

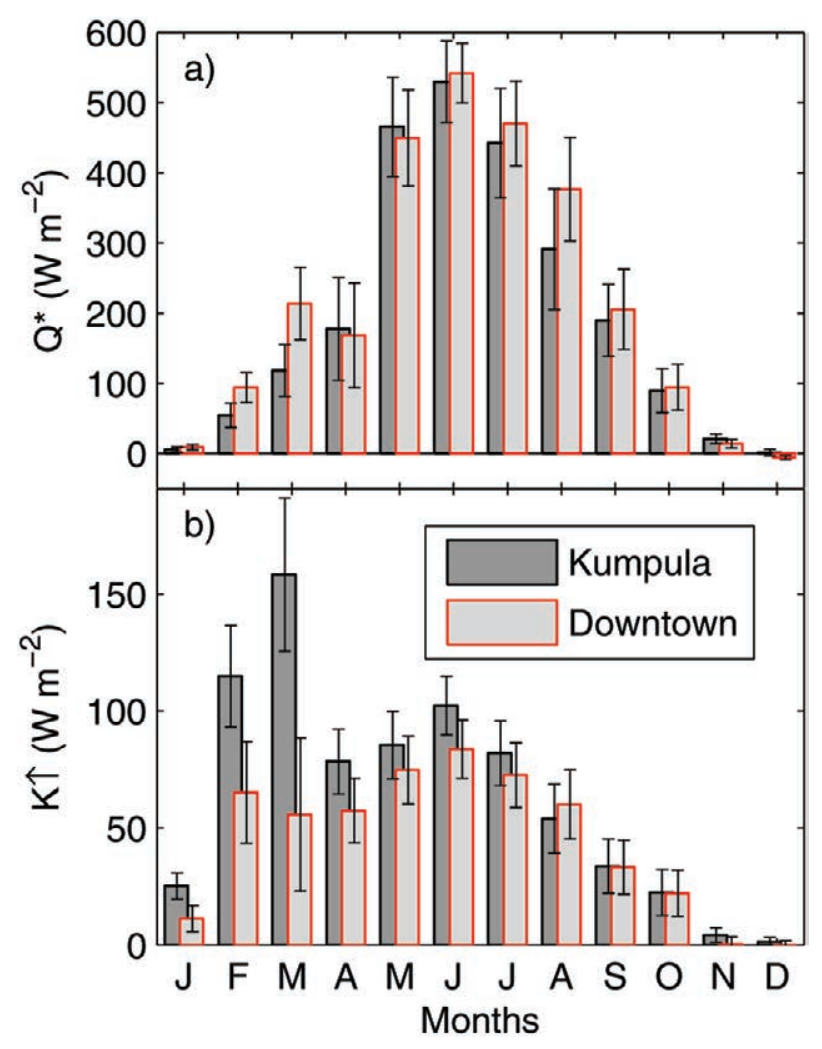

FIG. 2. Median monthly (a) net all-wave radiation and (b) upwelling shortwave radiation for $20 \mathrm{II}$ at Kumpula and downtown (Torni) calculated for times that are daytime throughout the year (0800-1200 UTC). The error bars show quartile deviations during the plotted hours. 
data for developing and assessing the parameterization of snow processes in atmospheric models.

The pattern of net all-wave radiation translates into the sensible heat flux $Q_{\mathrm{H}}$, which also experiences strong annual and diurnal variation (Fig. 3). First, it is perhaps obvious that the greatest sensible heat fluxes, of above $150 \mathrm{~W} \mathrm{~m}^{-2}$ at both sites, are observed in MayAugust during the daytime hours of 0600-1400 UTC. At Kumpula, there is little annual variation of sensible heat flux by night: the average is negative, although the average nocturnal sensible heat flux in winter is near zero. Downtown, the winter nights exhibit a mean positive sensible heat flux, although some cases of negative sensible heat flux can occur (see later case study). The strongest diurnal cycles in sensible heat flux occurred in spring and summer (especially

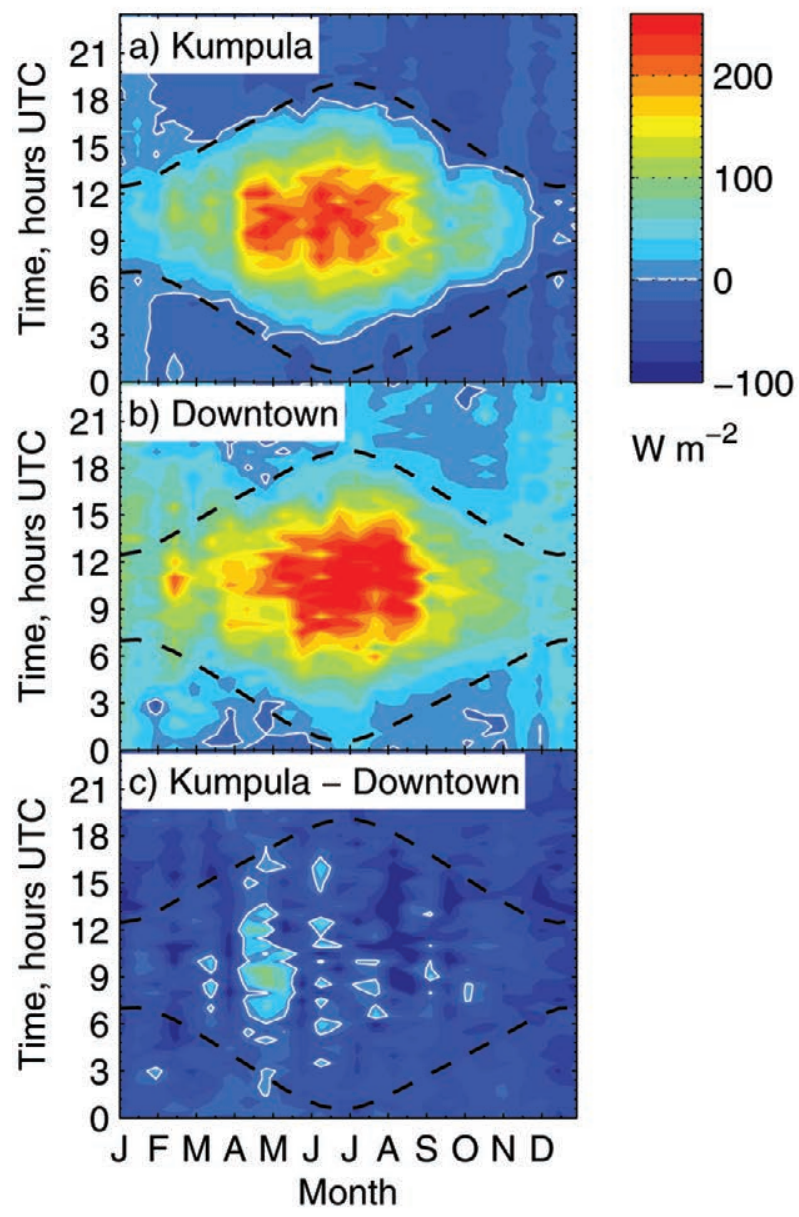

Fig. 3. Mean sensible heat flux for each $30-\mathrm{min}$ period for each month of $20 \mathrm{II}$ at (a) Kumpula and (b) downtown (Torni) and (c) their difference (same color scales in all subplots). Sunrise and sunset times are shown as thick dashed black lines. Zero sensible heat flux is shown as a white line. For all 30 -min periods in 2011 , negative sensible heat fluxes occurred $48 \%$ of the time at Kumpula and $13 \%$ of the time downtown (Torni). downtown). In winter, there is very little diurnal variation in the mean sensible heat flux at both sites especially under the cloudy snow-free conditions of November-December 2011. This is consistent with the near-zero net all-wave radiation (Fig. 2). When comparing the two sites, we see how the difference in sensible heat fluxes has a patchy pattern: the largest values occurring in late April-early May, between 0800 and 1200 UTC, with fluxes at Kumpula higher by over $50 \mathrm{~W} \mathrm{~m}^{-2}$ than downtown (also in 2012; not shown). At the same time, very high latent heat fluxes were not observed downtown, so we hypothesize these low $Q_{H}$ values downtown could be caused by heat storage flux to the cold building walls in spring. The storage heat flux typically peaks before midday and thus reduces available energy consumed in $Q_{\mathrm{H}}$ (Grimmond et al. 1991). This can be verified in the future when the seasonal behavior of the storage heat flux will be examined by modeling approaches. A diurnal pattern is also seen when comparing the two sites: greater daytime sensible heat fluxes are observed downtown than for Kumpula; this is likely a result of several factors including higher $Q^{*}$, anthropogenic heat emissions and heat storage, advection from the sea, and energy partitioning caused by a high fraction of vegetation at Kumpula.

A clear diurnal-cycle case study: 4 September 20II. To observe the evolution of the Helsinki ABL characteristics during a diurnal cycle, a day is chosen in the autumn with high atmospheric pressure (maximum $1015 \mathrm{hPa}$ ) and fair-weather cumulus (Fig. 4). A clear diurnal cycle is observed in many variables, such as relative humidity and upwelling longwave radiation, notwithstanding some additional synoptic changes, increase in wind speed and veer of wind with time.

Patterns in the thermal infrared (IR) camera data clearly show the main features of a warm surface by day and cool by night (Fig. 5). However, there is variability across the urban surface, primarily since surfaces facing different directions receive different solar irradiance. By day, a sharp temperature difference can be seen between the urban surface and the atmosphere, and a gradient in the atmosphere can also be seen, which is consistent with nearby vertical profiles of temperature (Fig. ES1 in the online supplement). The nocturnal IR data show a much more even distribution of temperature across the urban surfaces, compared with the values from the daytime. One possible implication is that modeling of daytime $\mathrm{ABL}$ conditions will require either high horizontal resolution or suitable aggregation of inhomogeneous forcing from the surface, while at 

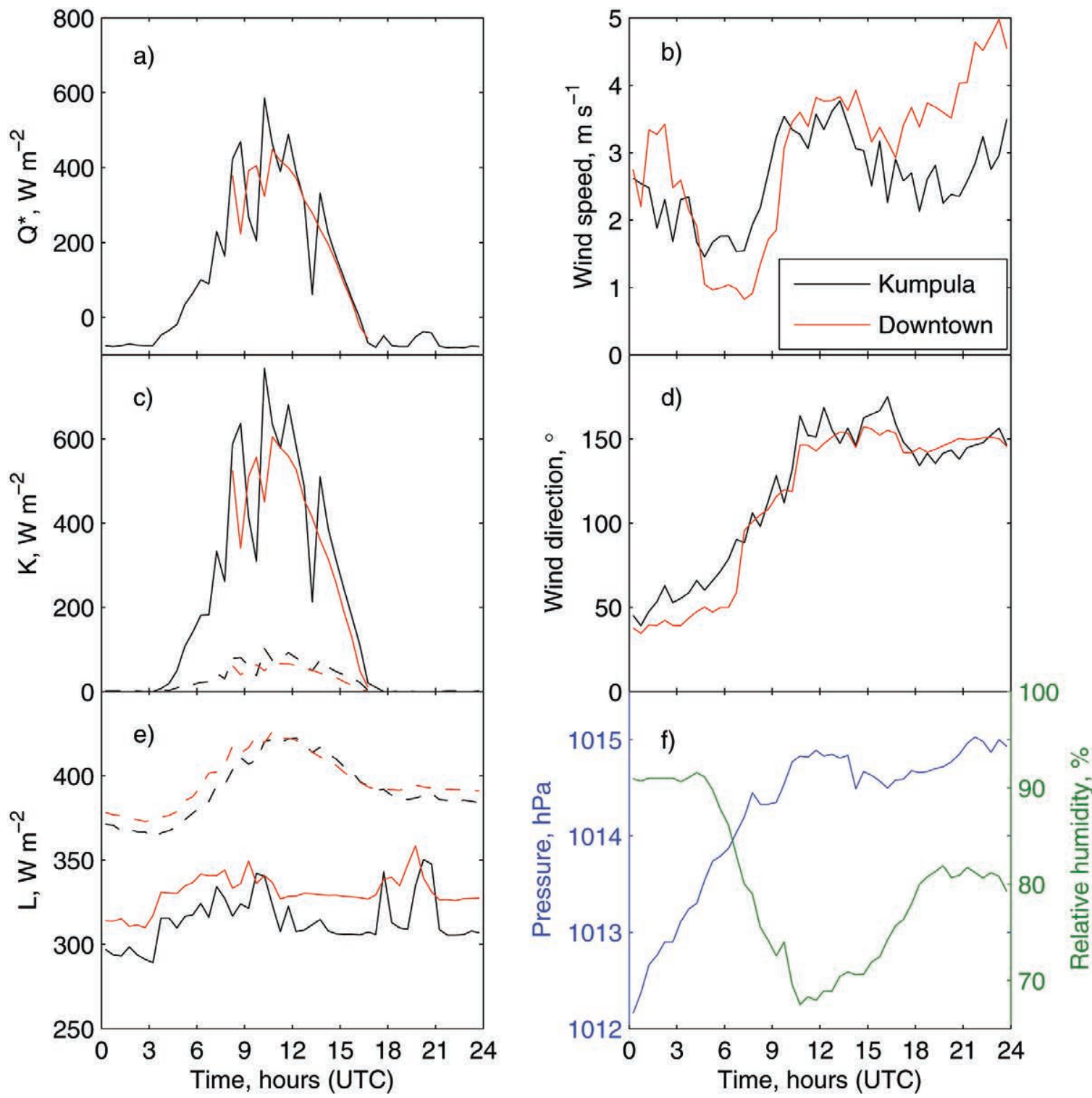

FIG. 4. Conditions in Helsinki on 4 Sep 20II, at Kumpula (black) and downtown (Torni; red) for (a) net all-wave radiation, (b) wind speed, (c) shortwave radiation, (d) wind direction, (e) longwave radiation, and (f) Kumpula pressure (blue) and relative humidity (green). Upwelling and downwelling radiation is marked with dashed and solid lines, respectively.

night vertical resolution would be more important. The IR camera could also be used to study the urbanspecific anthropogenic snowmelt from roofs that we hypothesize from Fig. $2 \mathrm{~b}$.

The evolution of ABL depth follows the expected pattern for clear-sky conditions (Fig. 6). A shallower $\mathrm{ABL}$ is observed with the sodar for stable/nighttime conditions between 100 and $150 \mathrm{~m}$ (unobservable by the lidar because of blind region of 0-90 m). By day, the ABL grows to a depth of greater than $400 \mathrm{~m}$ and is thus not observable with the sodar; the vertical profile of velocity variance in the lidar data indicates that the ABL depth was probably over
$1 \mathrm{~km}$ (crude estimation based on vertical-velocity variance limit of $0.1 \mathrm{~m}^{2} \mathrm{~s}^{-2}$; Barlow et al. 2011). There is temporal agreement in the turbulence regimes in the lidar and sodar: turbulence maximum by day and quiescent by night. However, because of signalto-noise constraints in the sodar velocity estimates, a quantitative comparison of vertical velocity cannot be made on this occasion. It is a major strength of an integrated observation network that we are able to observe the majority of shallow and deep ABLs by using both sodar and lidar at the same site but also to quantify on a long-term basis their differentiated observation methods of atmospheric vertical 
a)

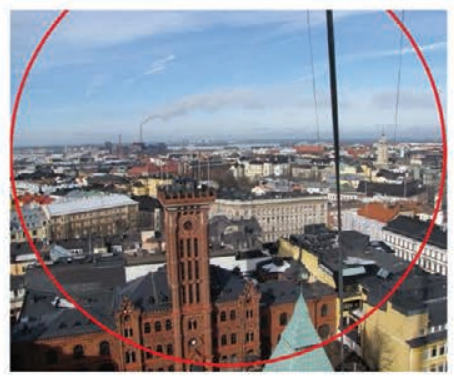

b)

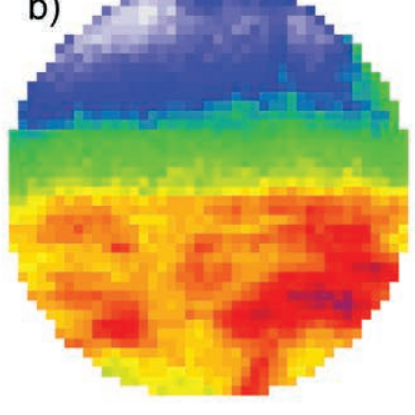

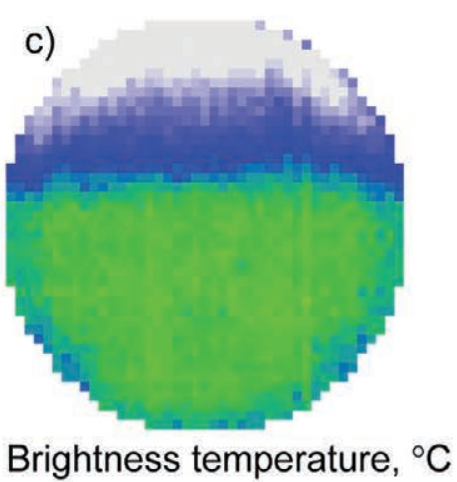

Fig. 5. Camera view [red circle in (a)] westward from Fire Station mast over downtown: (a) photograph taken 5 Apr 20II, with red-brick Fire Station tower in foreground; (b) thermal camera image at 1020 UTC 4 Sep 201 I (solar noon); and (c) thermal camera image at 2100 UTC 4 Sep 20II. The camera is centered so that the horizon equally bisects the image at the center.
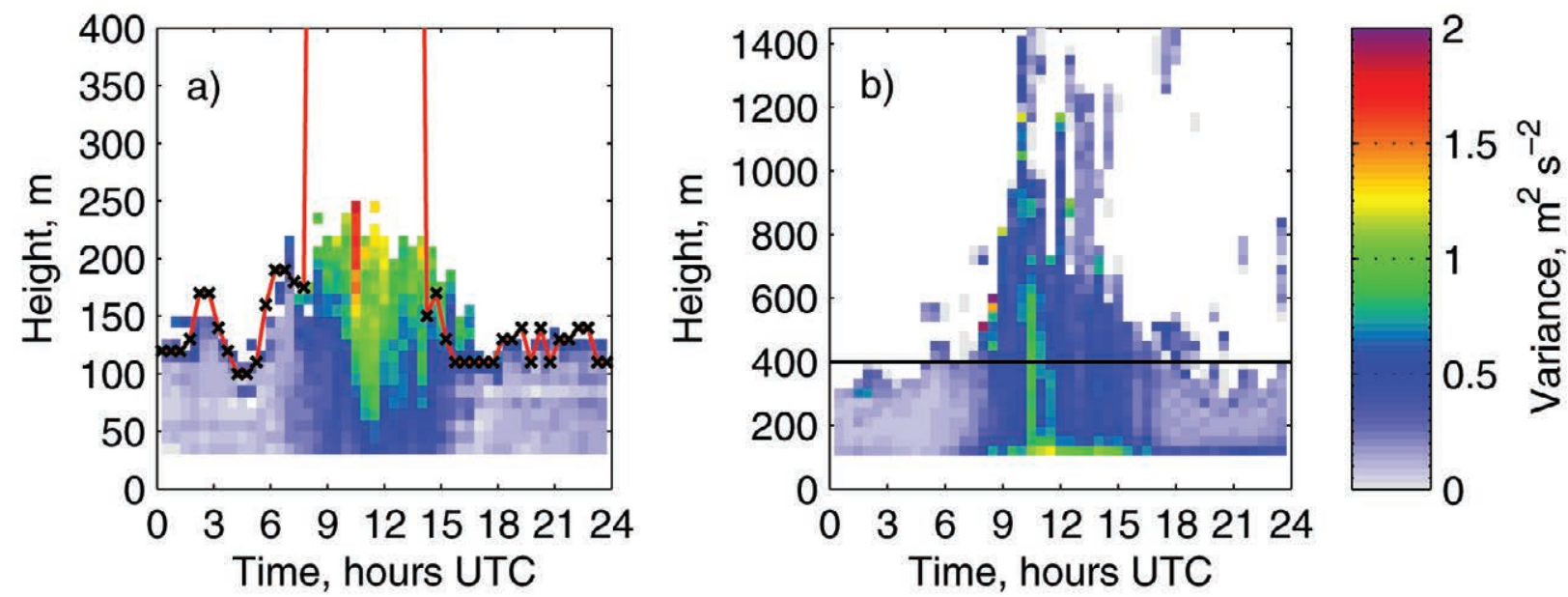

FIG. 6. Variance of vertical velocity $\left(\mathrm{m}^{2} \mathrm{~s}^{-2}\right)$ in Kumpula on 4 Sep $201 \mathrm{l}$ from (a) sodar and (b) lidar; the same color scale is used for both plots. The sodar's $400-\mathrm{m}$ range is marked also on the lidar panel (black line), easing comparison. The red line in (a) is the ABL depth estimated from sodar acoustic backscatter (Wood et al. 20I2).

structure inhomogeneities as a function of synoptic, stability, and surface conditions. Nevertheless, on some occasions the ABL depth cannot be determined since it is below even the height range of the sodar. Thus, a new lidar scanning technique within Helsinki UrBAN to cover these events is under development, since shallow ABLs are especially important for urban air quality.

The diurnal evolution is clearly seen in the time series of structure parameter of temperature (Fig. 7b). The greatest values (above $10^{-2} \mathrm{~K}^{2} \mathrm{~m}^{-2 / 3}$ ) are seen in the daytime, and the greatest values occur downtown as we would expect on the basis of greater positive sensible heat fluxes (Fig. 7a). On the other hand, the scintillometer curve does not follow the average $C_{\mathrm{T}}{ }^{2}$ values retrieved from downtown (Torni) and Kumpula sonics (at both ends of the scintillometer path), except late morning. We hypothesize that there is always some temperature gradient along the longer scintillometer beam due to the difference in stability cycle between downtown and semi-urban sites. This motivates detailed interpretation of the scintillometer path weighting together with footprint analysis and for additional point measurements between Kumpula and downtown.

The daytime unstable stratification lasts several hours longer downtown, particularly due to a later evening transition. The Kumpula time series of $Q_{H}$ goes from unstable through neutral (with $\mathrm{C}_{\mathrm{T}}{ }^{2}<$ $10^{-4} \mathrm{~K}^{2} \mathrm{~m}^{-2 / 3}$ ) to stable (with $C_{\mathrm{T}}{ }^{2} \approx 10^{-3} \mathrm{~K}^{2} \mathrm{~m}^{-2 / 3}$ after 1900 UTC), while downtown (Torni) the heat flux and $C_{\mathrm{T}}{ }^{2}$ show a longer period of neutral conditions. Persistence of neutral conditions may have been caused by greater anthropogenic heat release downtown and/or the evening increase in wind velocity observed downtown, but not at Kumpula (Fig. 4b). The 


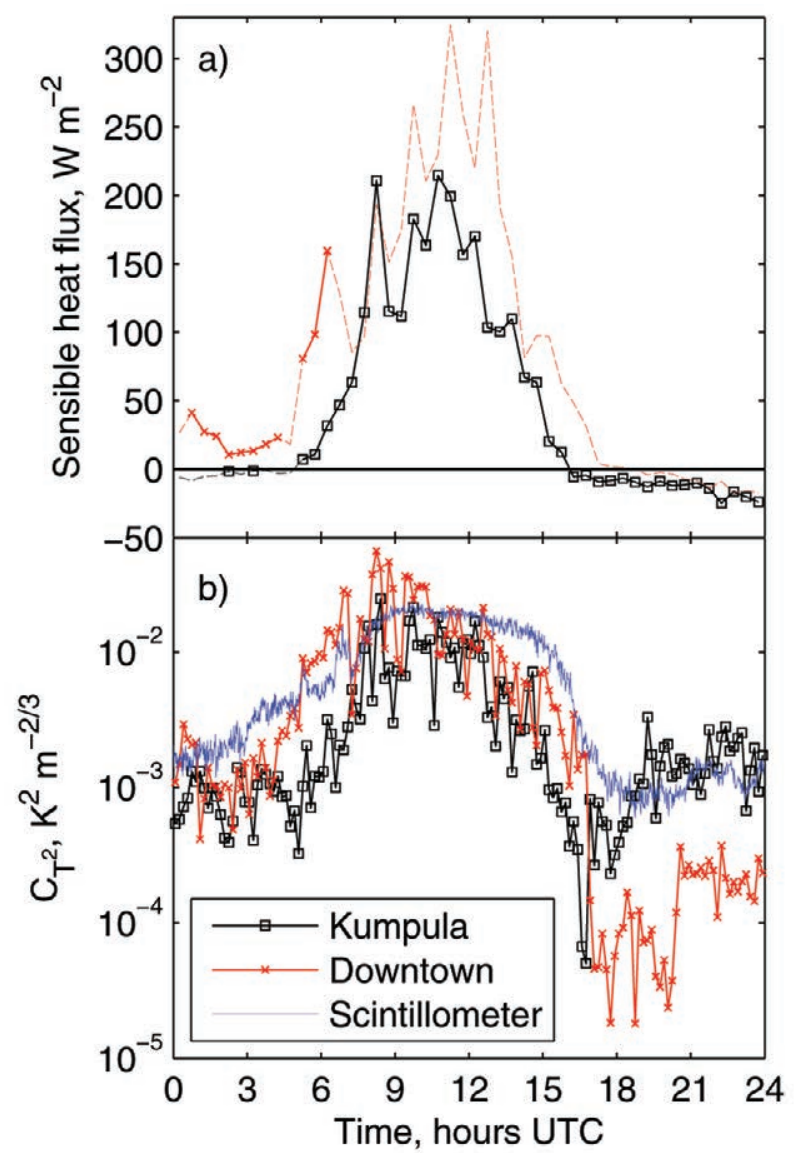

FIG. 7. Time series of (a) sensible heat flux and (b) structure parameter of temperature $\left(\mathrm{C}_{\mathrm{T}}{ }^{2}\right)$ on 4 Sep 20II. The city-scale scintillometer is from downtown (Torni) to Kumpula. Eddy-covariance data with thick lines and markers have stringent quality assurance, such as flux nonstationarity and mast interference (Nordbo et al. 20I2a); lighter dashed lines have less stringent quality assurance.

diurnal maximum in anthropogenic heat is usually observed after working hours, which coincides with the persistent positive $Q_{\mathrm{H}}$ downtown between 1500 and 1800 UTC (Sailor 2011).

It is noteworthy that sensible heat flux values are slightly positive or zero from 0000 to 0600 , while at 1600-2400 they go negative (stratification increasing) at both downtown and Kumpula sites. On the other hand, $C_{\mathrm{T}}^{2}$ values are closer together in the morning but strongly differ in the evening with the downtown values plummeting before settling. The semi-urban (Kumpula) $C_{\mathrm{T}}^{2}$ curve resets to its level as per morning (consistent with the same ABL depth estimates in morning and evening from sodar), while downtown the low $C_{\mathrm{T}}{ }^{2}$ value might indicate a different ABL height. These data show the interest of combining the different measuring approaches, which can reveal subtle differences even within a few kilometers range.

There are also possible complexities introduced by mesoscale changes such as topographical differences, varying closeness of sea bays along the path. Most scintillometer work has been conducted over homogeneous terrain (Moene et al. 2009). These preliminary results of structure parameters determined from different techniques over heterogeneous terrain indicate an overall qualitative agreement (Wood et al. 2013a); on the other hand, subtle differences open opportunities for more detailed investigations and understanding of intra-urban processes.

Given the evolution of $C_{\mathrm{T}}{ }^{2}$ and $Q_{\mathrm{H}}$, it is interesting that stable boundary layers might be coupled to a highly urbanized surface $(<10 \%$ occurrence downtown of negative $Q_{H}$ ). Even downtown (Torni) has occasionally stable flow (Nordbo et al. 2012a), perhaps partly explained by a small anthropogenic heat flux, more sustainable use of energy, and climatology.

A stable-atmosphere case study: 3 January 2012. Given the interest in stably stratified flow above a city, a second case study was chosen specifically where the Kumpula station had negative sensible heat fluxes even during daylight hours while the downtown station (Torni) had negative fluxes at night and for a short period in the afternoon (Fig. 8a). Despite the negative $Q_{H}$, the buoyancy term is very small in the turbulent kinetic energy budget (Fig. 8c) and it does not destroy the mechanically generated turbulence that is balanced out mainly by dissipation. The large mechanical production is urban specific, since the rough surface induces a high momentum flux. As a result, atmospheric stability is suppressed toward neutral in comparison with a less rough surface with an equivalent sensible heat flux. Some of the changes in stability are consistent with changes in cloud cover (Fig. 9), such as the stability going more stable between 0400 and 0700 UTC, when the sky was clear (Illingworth et al. 2007). There are few reports of stable stratification over cities (Fisher et al. 2005; Wood et al. 2010; Bergeron and Strachan 2012); our observations of stable stratification (13\% in 2011 at Torni; Fig. 3) motivate further our network due to a link to air quality: the largest particle fluxes and concentrations are observed at times of stability transition from stable to neutral (Figs. 8d,e). Nevertheless, it is hard to distinguish the effect of atmospheric stability versus that of traffic release since the stability transition and rush hour take place around the same time. Analyzing together atmospheric stability with traffic data will lead to an improved ability to predict 

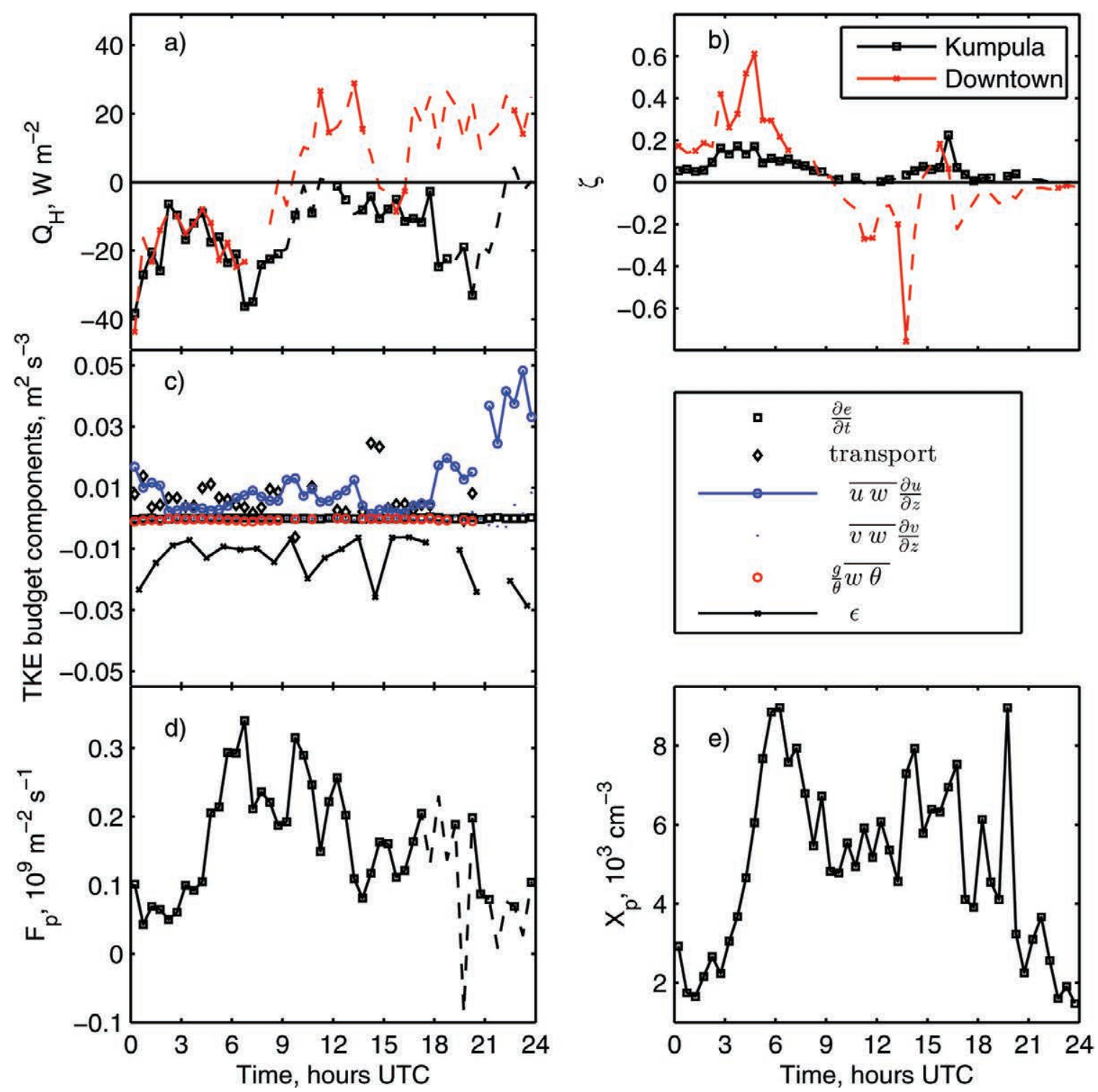

FIG. 8. Time series on 3 Jan 2012 of (a) sensible heat flux and (b) Monin-Obukhov stability parameter at Kumpula (black) and downtown (Torni, red), (c) turbulent kinetic energy budget at Kumpula, (d) particle flux at Kumpula, and (e) particle concentration at Kumpula. Data with thick lines and $x$ markers in (a),(b),(d),(e) have stringent quality assurance, such as flux nonstationarity and mast interference (Nordbo et al. 2012a); lighter dashed lines have less stringent quality assurance. The transport term in (c) is calculated as the residual of the other terms: time derivative of turbulent kinetic energy (black square), shear production in the streamwise (blue circle) and crosswind (blue dot) directions, buoyancy (red squares), and dissipation (black crosses).

Helsinki's air quality. One of the main purposes of the network is to improve the description of urban surface and the ABL in air-quality models, since stable urban ABLs are rarely observed in cities.

The lidar's custom scanning strategy allows a comparison between lidar and mast winds (Kumpula and downtown). The lidar operated a 10 -s sample every 5 min pointing due south at zero elevation. The data from the first usable range gate (gate 4) was compared with the northward component of horizontal wind from Kumpula (Fig. 10). Reassuringly a small rmse of $0.5 \mathrm{~m} \mathrm{~s}^{-1}$ (with respect to $0-8 \mathrm{~m} \mathrm{~s}^{-1} v$-component winds on this day) was observed for the 30 -min mean values on this day; indeed we would even expect some difference given the different spatial and temporal sampling of the two instruments. This highlights the potential of ground-based scanning lidar to reveal flow features over a city. 


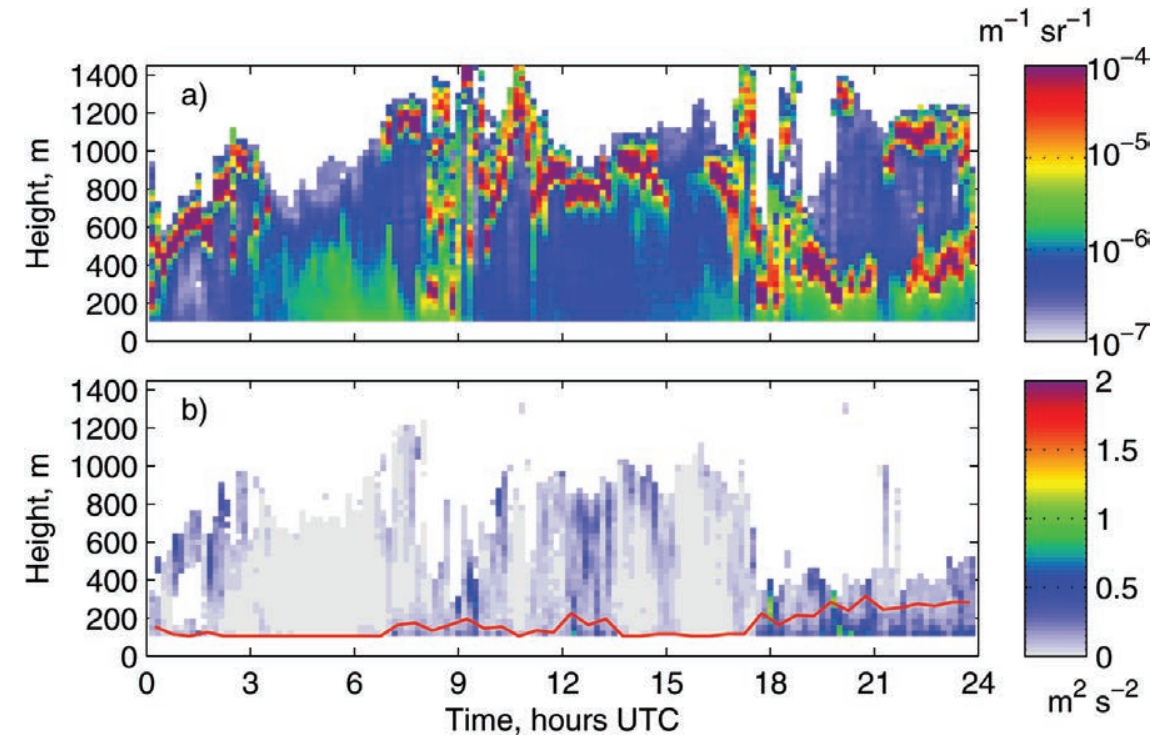

Fıg. 9. Vertical profiles from lidar at Kumpula on 3 Jan 2012. (a) Lidar backscatter values of $10^{-7}$ to $5 \times 10^{-6}$ are typically aerosol (blue and green), while values above $10^{-5}$ are cloud droplets (red). (b) Variance of vertical velocity, with 30-min mean threshold of $0.1 \mathrm{~m}^{2} \mathrm{~s}^{-2}$ (red) as a crude ABL depth estimator.

this network mainly since it forms the largest urban agglomeration in Finland (the Helsinki metropolitan area) and also because of logistical reasons (the location of the headquarters of the FMI and the University of Helsinki).

Data were shown to represent the potential of intensive state-of-the-art observations of the urban ABL. The results showed the range of stabilities for diurnal and annual cycles both downtown and at a semi-urban site: in particular, the seasonal cycle is pronounced. These results also show clear differences between sites at even modest distance, thus calling for

SUMMARY. The importance of long-term researchgrade observations of the urban ABL has led to the development of Helsinki UrBAN (http://urban.fmi.fi). This observation network has begun to improve our understanding of Helsinki's ABL. Components of the network have been running since 2004, with substantial expansion in 2010-2013. New equipment has been installed during the last few years: EC stations, scintillometers, sodar, lidar, and thermal IR camera.

Naturally, the network also has inherent limitations. (i) Although there are numerous non-urban background reference sites, these either have not been equipped with the same instrumentation as the corresponding urban sites (e.g., the radio tower measurements at the site of Kivenlahti, about $10 \mathrm{~km}$ west of downtown Helsinki; see online supplemental material) or are located at a substantial distance (e.g., SMEAR-II station at Hyytiälä, southern Finland, about $200 \mathrm{~km}$ north; Suni et al. 2003). (ii) The coastal location of Helsinki complicates the distinction of urban effects (Lowry 1977). However, 38\% of global population live within $50 \mathrm{~km}$ of the coastline (Kay and Alder 2005), increasingly many of them in urban environments, so, although the meteorology of coastal regions is more challenging to study than that of homogeneous inland sites, there is an evident need to study it (Mestayer et al. 2005). (iii) There are currently no in-canopy-layer measurements that would allow linking ABL climates to the canopy layer. Helsinki was selected as the location of more studies for better understanding of Helsinki's $\mathrm{ABL}$ processes affected by a range of surfaces. The examples in this paper have highlighted, for example, negative sensible heat fluxes over a city center with very low vegetation fraction, the applicability of urban

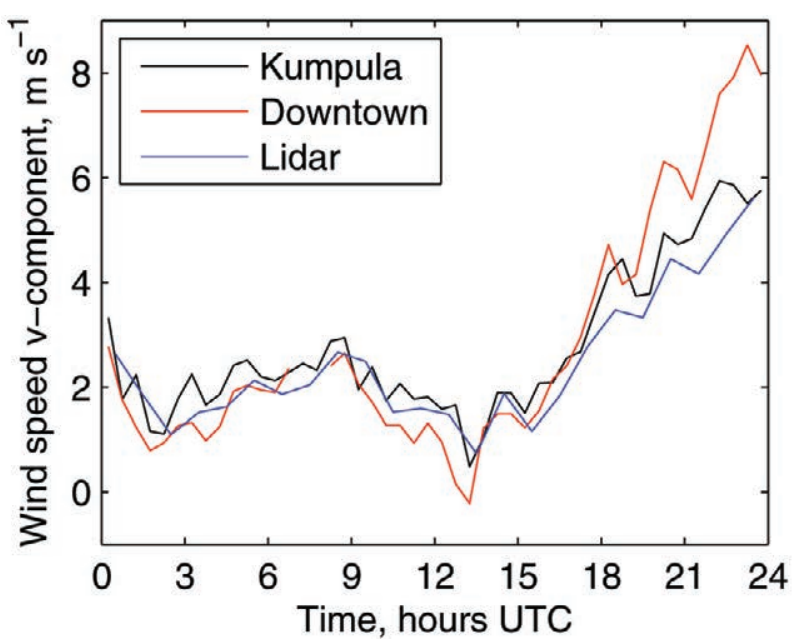

Fig. I0. Comparison of $30-\mathrm{min}$ mean northward $v$-component horizontal winds from sonic anemometer at Kumpula and downtown (Torni) with lidar beam pointing from Kumpula due south (range gate 4: 90-120 m) on 3 Jan 2012. Statistics between lidar and sonic anemometer at Kumpula from the 30-min data on this day are correlation coefficient of $\mathbf{0 . 9 6}$, root-mean-square difference of $0.52 \mathrm{~m} \mathrm{~s}^{-1}$, and bias of $-0.32 \mathrm{~m} \mathrm{~s}^{-1}$ (sonic anemometer greater than lidar). 
scintillometry, applying scanning lidar over a city, and the combination of sodar and lidar to give a fuller range of $\mathrm{ABL}$ depth estimates. There is also strong indication of the important role of the snow cover in the heat balance over the city. Previous studies in Helsinki have already reported many findings, such as analyses of fluxes (Vesala et al. 2008), exploitation of morphological datasets (Nordbo et al. 2012a), analysis of several years of $\mathrm{CO}_{2}$ fluxes (Järvi et al. 2012), and air-quality observations (www.airquality .fi; Pirjola et al. 2012).

These results will hopefully trigger modeling activities to distinguish and prioritize the various processes at hand. Beyond the forthcoming science outputs, we expect to expand this network. We anticipate that others will bring their equipment and/or expertise alongside ours for the development of technology, science, and applications.

ACKNOWLEDGMENTS. EC FP7 ERC Grant 227915 "Atmospheric planetary boundary layers-Physics, modelling and role in Earth system" and the Academy of Finland (Projects 138328, 1118615, and ICOS-Finland, 263149) provided financial support. Kari Riikonen, Erkki Siivola, Pasi Aalto, and Petri Keronen provided technical support; Kari Niemelä extracted AMDAR data (online supplemental materials). We had useful discussions with Iolanda Iolongo, Mari Kauhaniemi, Juuso Suomi, Jukka Käyhkö, Anu Kousa, Tarja Koskentalo, Heikki Turtiainen, Mikko Laakso, Reijo Roininen, Antti Hellsten, Adriaan Perrels, Mika Komppula, Elena Saltikoff, Sue Grimmond, and Janet Barlow. We are very grateful for the insightful and constructive comments from the reviewers.

\section{REFERENCES}

Allwine, K. J., and J. E. Flaherty, 2006: Joint Urban 2003: Study overview and instrument locations. Pacific Northwest National Laboratory Rep. PNNL-15967, 92 pp.

Aubinet, M., T. Vesala, and D. Papale, 2012: Eddy Covariance: A Practical Guide to Measurement and Data Analysis. Springer, 438 pp.

Barlow, J. F., T. M. Dunbar, E. G. Nemitz, C. R. Wood, M. W. Gallagher, F. Davies, E. O'Connor, and R. M. Harrison, 2011: Boundary layer dynamics over London, UK, as observed using Doppler lidar during REPARTEE-II. Atmos. Chem. Phys., 11, 2111-2125.

Bergeron, O., and I. B. Strachan, 2012: Wintertime radiation and energy budget along an urbanization gradient in Montreal, Canada. Int. J. Climatol., 32, $137-152$.
Changnon, S. A., F. A. Huff, and R. G. Semonin, 1971: METROMEX: An investigation of inadvertent weather modification. Bull. Amer. Meteor. Soc., 52, 958-968.

Collier, C. G., and Coauthors, 2005: Dual-Doppler lidar measurements for improving dispersion models. Bull. Amer. Meteor. Soc., 86, 825-838.

Cros, B., and Coauthors, 2004: The ESCOMPTE program: An overview. Atmos. Res., 69, 241-279.

Eresmaa, N., A. Karppinen, S. M. Joffre, J. Räsänen, and H. Talvitie, 2006: Mixing height determination by ceilometer. Atmos. Chem. Phys., 6, 1485-1493.

—, N., J. Härkönen, S. M. Joffre, D. M. Schultz, A. Karppinen, and J. Kukkonen, 2012: A three-step method for estimating the mixing height using ceilometer data from the Helsinki Testbed. J. Climate Appl. Meteor., 51, 2172-2187.

Fisher, B., S. Joffre, J. Kukkonen, M. Piringer, M. Rotach, and M. Schatzmann, 2005: Meteorology applied to urban air pollution problems. COST Action 715 Final Rep., 276 pp.

Grimmond, C. S. B., 2006: Progress in measuring and observing the urban atmosphere. Theor. Appl. Climatol., 84, 3-22.

— H. A. Cleugh, and T. R. Oke, 1991: An objective urban heat storage model and its comparison with other schemes. Atmos. Environ., 25B, 311-326.

Hanna, S. R., and Coauthors, 2006: Detailed simulations of atmospheric flow and dispersion in downtown Manhattan: An application of five computational fluid dynamics models. Bull. Amer. Meteor. Soc., 87, 1713-1726.

Harrison, R. M., and Coauthors, 2012: Atmospheric chemistry and physics in the atmosphere of a developed megacity (London): An overview of the REPARTEE experiment and its conclusions. Atmos. Chem. Phys., 12, 3065-3114.

Hill, R. J., and G. R. Ochs, 1978: Fine calibration of large-aperture optical scintillometers and an optical estimate of inner scale of turbulence. Appl. Opt., 17, 3608 .

Hirsikko, A., and Coauthors, 2013: Observing wind, aerosol particles, cloud and precipitation: Finland's new ground-based remote-sensing network. Atmos. Meas. Tech. Discuss., 6, 7251-7313, doi:10.5194/ amtd-6-7251-2013.

HSY, 2008: SeutuCD. Helsinki Region Environmental Services Authority dataset, CD-ROM.

Hussein, T., and Coauthors, 2008: Observation of regional new particle formation in the urban atmosphere. Tellus, 60B, 509-521.

Illingworth, A. J., and Coauthors, 2007: Cloudnet. Bull. Amer. Meteor. Soc., 88, 883-898. 
Järvi, L., and Coauthors, 2009a: Annual particle flux observations over a heterogeneous urban area. Atmos. Chem. Phys., 9, 7847-7856.

— and Coauthors, 2009b: The urban measurement station SMEAR III: Continuous monitoring of air pollution and surface-atmosphere interactions in Helsinki, Finland. Boreal Environ. Res., 14, 86-109. — and Coauthors, 2009c: Comparison of net $\mathrm{CO}_{2}$ fluxes measured with open- and closed-path infrared gas analyzers in an urban complex environment. Boreal Environ. Res., 14, 499-514.

—, I. Mammarella, W. Eugster, A. Ibrom, E. Siivola, E. Dellwik, P. Keronen, and G. Burba, 2009d: Comparison of net $\mathrm{CO}_{2}$ fluxes measured with open- and closed-path infrared gas analyzers in an urban complex environment. Boreal Environ. Res., 6095, 499-514.

- A. Nordbo, H. Junninen, A. Riikonen, J. Moilanen, E. Nikinmaa, and T. Vesala, 2012: Seasonal and annual variation of carbon dioxide surface fluxes in Helsinki, Finland, in 2006-2010. Atmos. Chem. Phys., 12, 8475-8489.

Kay, R., and J. Alder, 2005: Coastal Planning and Management. 2nd ed. Taylor and Francis, 400 pp.

Koskinen, J. T., and Coauthors, 2011: The Helsinki Testbed: A mesoscale measurement, research, and service platform. Bull. Amer. Meteor. Soc., 92, 325-342.

Kouznetsov, R. D., 2007: Latan-3 sodar for investigation of the atmospheric boundary layer. Atmos. Oceanic Opt., 20, 684-687.

_- 2009: The multiple-frequency sodar with high temporal resolution. Meteor. Z., 18, 163-167.

_- and M. Kallistratova, 2010: Anisotropy of a smallscale turbulence in the atmospheric boundary layer and its effect on acoustic backscattering. Extended Abstracts, Int. Symp. for the Advancement of Boundary Layer Remote Sensing, Paris, France.

Kukkonen, J., and Coauthors, 2005: Analysis and evaluation of selected local-scale PM air pollution episodes in four European cities: Helsinki, London, Milan and Oslo. Atmos. Environ., 39, 2759-2773.

_ - and Coauthors, 2012: A review of operational, regional-scale, chemical weather forecasting models in Europe. Atmos. Chem. Phys., 12, 1-87.

Kupiainen, K., L. Pirjola, R. Ritola, O. Väkevä, J. Viinanen, A. Stojiljkovic, and A. Malinen, 2011: Street dust emissions in Finnish cities-Summary of results from 2006-2010. City of Helsinki Environment Centre Rep. 5/2011, 81 pp.

Lemonsu, A., and Coauthors, 2008: Overview and first results of the Montreal Urban Snow Experiment 2005. J. Climate Appl. Meteor., 47, 59-75.

- , and Coauthors, 2010: Evaluation of the town energy balance model in cold and snowy conditions during the Montreal Urban Snow Experiment 2005. J. Climate Appl. Meteor., 49, 346-362.

Lowry, W. P., 1977: Empirical estimation of urban effects on climate: A problem analysis. J. Appl. Meteor., 16, 129-135.

Mårtensson, E. M., E. D. Nilsson, G. Buzorius, and C. Johansson, 2006: Eddy covariance measurements and parameterisation of traffic related particle emissions in an urban environment. Atmos. Chem. Phys., 6, 769-785.

Masson, V., 2000: A physically-based scheme for the urban energy budget in atmospheric models. Bound.Layer Meteor., 94, 357-397.

_- and Coauthors, 2008: The Canopy and Aerosol Particles Interactions in Toulouse Urban Layer (CAPITOUL) experiment. Meteor. Atmos. Phys., 102, 135-157.

Mestayer, P. G., and Coauthors, 2005: The urban boundary-layer field campaign in Marseille (UBL/ CLU-ESCOMPTE): Set-up and first results. Bound.Layer Meteor., 114, 315-365.

Moene, A. F., O. K. Hartogensis, and F. Beyrich, 2009: Developments in scintillometry. Bull. Amer. Meteor. Soc., 90, 694-698.

Nordbo, A., L. Järvi, S. Haapanala, J. Moilanen, and T. Vesala, 2012a: Intra-city variation in urban morphology and turbulence structure in Helsinki, Finland. Bound.-Layer Meteor., 146, 469-496.

,,,--- C. R. Wood, and T. Vesala, 2012b: Fraction of natural area as main predictor of net $\mathrm{CO}_{2}$ emissions from cities. Geophys. Res. Lett., 39, L20802, doi:10.1029/2012GL053087.

_ _ _ _ and T. Vesala, 2012c: Revised eddy covariance flux calculation methodologies-Effect on urban energy balance. Tellus, 64B, 18 184, doi:10.3402/ tellusb.v64i0.18184.

O'Connor, E. J., A. J. Illingworth, and R. J. Hogan, 2004: A technique for autocalibration of cloud lidar. J. Atmos. Oceanic Technol., 21, 777-786.

Oke, T. R., 1987: Boundary Layer Climates. Routledge, $435 \mathrm{pp}$.

Pearson, G., F. Davies, and C. Collier, 2009: An analysis of the performance of the UFAM pulsed Doppler lidar for observing the boundary layer. J. Atmos. Oceanic Technol., 26, 240-250.

Pirinen, P., H. Simola, J. Aalto, J.-P. Kaukoranta, P. Karlsson, and R. Ruuhela, 2012: Climatological statistics of Finland 1981-2010. Finnish Meteorological Institute Rep. 1, 96 pp.

Pirjola, L., and Coauthors, 2012: Spatial and temporal characterization of traffic emissions in urban microenvironments with a mobile laboratory. Atmos. Environ., 63, 156-167. 
Population Register Center of Finland, cited 2012: Population by municipality as of 31 January 2012 (in Finnish and Swedish). Population Information System Rep. [Available online at www.vrk.fi/.]

Ripamonti, G., L. Järvi, B. Mølgaard, T. Hussein, A. Nordbo, and K. Hämeri, 2013: The effect of local sources on aerosol particle number size distribution, concentrations and fluxes in Helsinki, Finland. Tellus, 65, 19786, doi:10.3402/tellusb.v65i0.19786.

Rotach, M. W., B. Fisher, and M. Piringer, 2002: COST 715 Workshop on Urban Boundary Layer Parameterizations. Bull. Amer. Meteor. Soc., 83, 1501-1504.

— , and Coauthors, 2005: BUBBLE-An urban boundary layer meteorology project. Theor. Appl. Climatol., 81, 231-261.

Roth, M., 2000: Review of atmospheric turbulence over cities. Quart. J. Roy. Meteor. Soc., 126, 941-990.

Saarnio, K., K. Teinilä, M. Aurela, H. Timonen, and R. Hillamo, 2010: High-performance anion-exchange chromatography-mass spectrometry method for determination of levoglucosan, mannosan, and galactosan in atmospheric fine particulate matter. Anal. Bioanal. Chem., 398, 2253-2264.

Sailor, D. J., 2011: A review of methods for estimating anthropogenic heat and moisture emissions in the urban environment. Int. J. Climatol., 31, 189-199.
Schneider, A., M. A. Friedl, and D. Potere, 2009: A new map of global urban extent from MODIS satellite data. Environ. Res. Lett., 4, 044003 doi:10.1088/17489326/4/4/044003.

Scintec, 2011: Scintec boundary layer scintillometer hardware manual. Version 2.07, Scintec, 67 pp.

Suni, T., and Coauthors, 2003: Long-term measurements of surface fluxes above a Scots pine forest in Hyytiälä, southern Finland, 1996-2001. Boreal Environ. Res., 8, 287-301.

Suomi, I., 2004: Fog over the Gulf of Finland on 8 September, 2002 (in Finnish). M.S. thesis, Dept. of Physics, University of Helsinki, 54 pp.

Tammelin, B., and Coauthors, 2012: Production of the Finnish wind atlas. Wind Energy, 16, 19-35.

Uijlenhoet, R., J.-M. Cohard, and M. Gosset, 2011: Pathaverage rainfall estimation from optical extinction measurements using a large-aperture scintillometer. J. Hydrometeor., 12, 955-972.

Vesala, T., and Coauthors, 2008: Surface-atmosphere interactions over complex urban terrain in Helsinki, Finland. Tellus, 60, 188-199.

Vihma, T., and B. Brümmer, 2002: Observations and modelling of on-ice and off-ice flows in the northern Baltic Sea. Bound.-Layer Meteor., 103, 1-27.

Wood, C. R., and Coauthors, 2009: Dispersion experiments in central London: The 2007 DAPPLE project. Bull. Amer. Meteor. Soc., 90, 955-969.

— height above London during 2006-2008: A climatology and the applicability of similarity theory. Bound.-Layer Meteor., 137, 77-96.

—, R. D. Kouznetsov, and A. Karppinen, 2012: An automatic algorithm for detecting mixing-height from SODAR. Proc. 16th Int. Symp. for the Advancement of Boundary Layer Remote Sensing, Boulder, CO, NOAA/ERSL, 102-105.

,,-- R. Gierens, A. Nordbo, L. Järvi, M. A. Kallistratova, and J. Kukkonen, 2013a: On the temperature structure parameter and sensible heat flux over Helsinki from sonic anemometry and scintillometry. J. Atmos. Oceanic Technol., 30, 1604-1615.

—, L. Pauscher, S. Kotthaus, J. F. Barlow, H. Ward, S. Lane, and S. Grimmond, 2013b: Wind observations over the River Thames in central London. Sci. Total Environ., 442, 527-533.

Zeweldi, D. A., M. Gebremichael, J. Wang, T. Sammis, J. Kleissl, and D. Miller, 2009: Intercomparison of sensible heat flux from large aperture scintillometer and eddy covariance methods: Field experiment over a homogeneous semi-arid region. Bound.-Layer Meteor., 135, 151-159. 